\title{
INFECÇÕES DE TECIDOS MOLES ERISIPELA. CELULITE. SÍNDROMES INFECCIOSAS MEDIADAS POR TOXINAS
}

\author{
SOFT TISSUE INFECTIONS \\ ERYSIPELA. CELLULITIS. INFECTIOUS SYNDROMES MEDIATED BY TOXINS
}

Cacilda da Silva Souza ${ }^{1}$

1'Docente. Divisão de Dermatologia. Departamento de Clínica Médica. Faculdade de Medicina de Ribeirão Preto - USP. CorResPondêncIA: Divisão de Dermatologia. Hospital das Clínicas - Av. Bandeirantes, $3900-4^{0}$ andar - CEP $14048-900$ - Ribeirão Preto -SP.

SOUZA CS. Infecções de tecidos moles - Erisipela. Celulite. Síndromes infecciosas mediadas por toxinas. Medicina, Ribeirão Preto, 36: 351-356,abr./dez.2003.

RESUMO - Nesta revisão são abordados a etiologia e os principais aspectos clínicos, dermatológicos e terapêuticos das infecções de tecidos moles e das síndromes infecciosas mediadas por toxinas.

UNITERMOS - Erisipela. Celulite. Síndrome Estafilocócica da Pele Escaldada. Síndrome do Choque Tóxico.

Infecções dos tecidos moles são caracterizadas por inflamação aguda, difusa, edematosa, supurativa e disseminada, que atinge a derme e o subcutâneo e a elas, freqüentemente, estão associados sintomas sistêmicos, como mal-estar, febre e calafrios. Infecções necrotizantes dos tecidos moles atingem o subcutâneo profundamente, resultam na destruição da fáscia e do tecido gorduroso e são potencialmente fatais, requerendo, em adição, desbridamento cirúrgico extensivo $^{(1,2,3)}$.

\section{ERISIPELA/CELULITE}

Erisipela é um distinto tipo de celulite cutânea, superficial, com marcante envolvimento de vasos linfáticos da derme. Na erisipela típica, a área de inflamação destaca-se com algum relevo, indicando distinta demarcação entre o tecido envolvido e o normal. É causada por estreptococos $\beta$ - hemolítico, do grupo A (EGA), menos freqüente do grupo $\mathrm{C}$ ou $\mathrm{G}$ e, mais raramente, por Staphylococcus aureus. A erisipela por estreptococos $\beta$ - hemolítico, do grupo A é a causa mais comum de infecção grave dos tecidos moles em indivíduos saudáveis. Celulite é o processo que atinge derme profunda e tecido subcutâneo e nem sempre é clara a distinção entre tecido infectado e não infectado. S. aureus e estreptococos do grupo A são os agentes etiológicos mais comuns da celulite, mais ocasionalmente, outras bactérias podem ser implicadas, como Haemophilus influenzae, bacilos Gram-negativos e, ainda, fungos, como Cryptococcus neoformans ${ }^{(1,2,3)}$. Embora as duas condições, erisipela e celulite, quando típicas, possam ser distinguíveis, há uma variabilidade do envolvimento tecidual, que torna a diferenciação nem sempre tão clara. Ambas as condições apresentam manifestações de sinais locais de inflamação (eritema, edema, calor e dor) e, na maioria das instâncias, febre e leucocitose, sendo linfangite e/ou linfadenite também freqüentes ${ }^{(3)}$.

A pele normal possui papel crítico na defesa contra uma variedade de patógenos. A interação entre patógeno e hospedeiro ainda não é totalmente elucidada e estariam envolvidos fatores bacterianos, funções de barreira da pele e fatores do hospedeiro. A infecção cutânea, frequientemente, surge em decorrência de ruptura da integridade da epiderme. A 
infecção instala-se com a invasão da derme e do subcutâneo pelo patógeno e mecanismos inflamatórios são elicitados como resposta à invasão. Nem sempre é possível o isolamento do microorganismo, sugerindo que muitas das alterações clínicas locais são mediadas por citocinas e/ou toxinas. A porta de entrada pode ser distante, a exemplo das fissuras interdigitais da tinha dos pés, associadas à celulite acima do tornozelo ou da erisipela da face em decorrência da colonização da nasofaringe por estreptococos do grupo A, particularmente, em quadros de rinite e sinusite. Há casos em que a porta de entrada não é aparente e, nem tampouco são evidentes os focos locais e ou distantes de infecção ${ }^{(1)}$. A celulite pode ocorrer por meio de porta de entrada em qualquer local mucocutâneo ou, menos comumente, por via hematogênica até os tecidos frouxos. Os patógenos transportados pelo sangue que causam celulite são Streptococcus pneumoniae, Vibrio vulnificus e Criptococcus neoformans.

A flora cutânea normal é composta por estafilococos coagulase negativos, difteróides aeróbicos (Corynebacterium spp) e difteróides anaeróbicos (Propioniobacterium acnes). Se a flora normal é erradicada ou diminuída, espécies patogênicas podem proliferar-se. Uma vez estabelecida, a infecção se propaga através de espaços teciduais e planos de clivagem por ação das hialuronidases, fibrinolisinas e lecitinases. Há, também, a propensão de invasão de vasos linfáticos e sanguíneos, resultando em linfangite, linfadenite, bacteriemia e septicemia. A produção local de exotoxinas, no sítio de infecção pelo $S$. aureus, pode resultar em síndrome da pele escaldada estafilocócica (SPEE) e a síndrome do choque tóxico (SCT). As condições fisiológicas e circulatórias locais e o status imunológico do indivíduo são os maiores determinantes de defesa do hospedeiro contra os patógenos. Linfaedema associado à drenagem linfática anormal, insuficiência venosa crônica e a síndrome nefrótica predispõem a celulite. O primeiro episódio de celulite, freqüentemente, compromete vasos linfáticos e predispõe a celulites recorrentes, linfaedema crônico e elefantíase. Infecções de membros inferiores podem ser complicadas por tromboflebites ${ }^{(1,2)}$.

Em alguns casos, há história de lesão precedente (úlcera de estase, ferida por punctura). Com a instalação da infecção, os pacientes experimentam dor, edema, eritema e calor locais, associados a variáveis graus de sintomas sistêmicos, resultantes da disseminação da infecção: indisposição, anorexia, febre e calafrios. Em alguns indivíduos, sintomas sistêmicos po- dem anteceder os sinais e sintomas locais da infecção. O eritema, no sítio da infecção, rapidamente se intensifica e amplia, e a dor torna-se marcante. $\mathrm{Na}$ erisipela, a área afetada apresenta borda nítida, que avança com a progressão da infecção. Vesículas, bolhas, erosões, úlceras, abscessos e necrose podem sobrepor-se à placa eritematoedematosa. Adenite satélite da região comprometida acompanha o quadro e a linfangite pode estar presente. Os membros inferiores são locais mais acometidos em adultos, seguidos dos membros superiores e da face. A porta de entrada com solução de continuidade decorrente de dermatoses subjacentes, traumatismos e infecção de mucosa, pode não ser evidenciada. Tinha interdigital, ferimentos, picadas de insetos, uso de drogas injetáveis, feridas cirúrgicas, queimaduras, laceração, entre outros, são as portas de entrada mais comuns da erisipela/celulite. Ressaltamos, entre as principais dermatoses subjacentes, as doenças bolhosas (pênfigos e penfigóides), infecções virais (herpes simples e zoster), dermatofitoses, dermatoses inflamatórias (dermatite de estase, atópica e de contato), piodermites superficiais (impetigo, foliculite, furunculose) e úlceras de diversas etiologias ${ }^{(1,2)}$.

Enquanto erisipelas clássicas são virtualmente causadas por estreptococos $\beta$ - hemolítico, do grupo A (EGA), o diagnóstico diferencial das celulites é mais problemático. A seguir, destacaremos pontos relevantes que podem contribuir na distinção das variantes das celulites $^{(1,2)}$ :

Celulite causada pelo $S$. aureus: em geral, a porta de entrada é evidente e, com frequiência, há infecção local. É um processo comum em usuários de drogas. O patógeno também está associado às síndromes mediadas por toxinas (síndrome da pele escaldada e síndrome do choque tóxico) e à endocardite após bacteriemia.

Celulite causada pelo estreptococo do grupo B: colonizadores da região anogenital causam celulite que pode se estender aos tecidos pélvicos.

Celulite causada pelo Streptococcus pneumoniae: em geral, associa-se aos quadros de imunocomprometimento.

Celulite causada por Haemophilus influenzae: ocorre, principalmente, em crianças menores de 2 anos não vacinadas contra $\mathrm{HiB}$, com localização preferencial no segmento cefálico (área periorbitária e região malar).

Celulite causada pelo Vibrio vulnificus: presença de distúrbios subjacentes, como cirrose, diabe- 
tes e outras condições imunossupressoras. Ocorre depois da ingestão de frutos do mar crus e mal cozidos, seguida da gastroenterite e bacteriemia com disseminação para a pele. A infecção é caracterizada pela presença de bolhas e vasculite necrotizante. Geralmente, as lesões acometem as extremidades e, com freqüência, bilateralmente.

Celulite causada pelo complexo Mycobacterium chelonei - M. fortuitum: História de cirurgia, injeção ou ferida penetrante recente. Celulite branda, sem manifestações sistêmicas.

Celulite criptocócica: apresenta associação com condições de imunossupressão. Caracteriza-se por placa vermelha, quente, dolorosa e edemaciada na extremidade, pode evoluir com necrose.

Infecções necrotizantes dos tecidos moles (INTM): diferem das outras variantes pela presença de significativa necrose tecidual, inexistência de resposta ao tratamento isolado com antimicrobianos e necessidade do desbridamento cirúrgico dos tecidos desvitalizados. O eritema e a induração dolorosa dos tecidos subjacentes são seguidos rapidamente por escara enegrecida, necrose liquefeita e fétida. Subdividem-se em celulite necrotizante, fascí́te necrotizante e mionecrose. As INTMs da região perineal são conhecidas como gangrena de Fournier.

A exemplo da fasciíte necrotizante, estreptocócica, previamente chamada de gangrena estreptocócica, o primeiro indício clínico da infecção é o edema difuso do membro afetado, seguido por formação de bolha de conteúdo hialino, que, rapidamente, torna-se de cor marrom ou violácea. Se intervenção apropriada não for realizada, tal processo evolui com franca rapidez para gangrena cutânea, algumas vezes com mionecrose e extensão do processo inflamatório para o plano fascial. Há dificuldades na distinção entre quadros iniciais da celulite e da fasciíte necrotizante. Com a evolução, essa distinção torna-se crucial, pois a fasciíte necrotizante requer desbridamento cirúrgico, concomitante ao uso da terapêutica antimicrobiana, e associa-se comumente a episódio precoce de choque e de falência de órgãos, por definição, a síndrome do choque tóxico estreptocócico.

\section{Diagnósticos diferenciais ${ }^{(1,2)}$}

Erisipela/ celulite: trombose venosa profunda e tromboflebite; dermatite de estase; dermatite de contato, em fase inicial; eritema nodoso; eritema migratório (borreliose de Lyme); fase pré-vesiculosa do herpes zoster; eritema pigmentar fixo, por droga; urticária gigante e celulite eosinofílica.
Infecções necrotizantes dos tecidos moles (INTM): vasculites, embolia com infarto cutâneo, doença vascular periférica, púrpura fulminante, calciofilaxia, necrose causada por varfarina, lesão traumática e acidente por aracnídeo.

\section{Exames laboratoriais e tratamento}

Salvo se a coleta do exsudato permita a coloração por Gram e a cultura ou, ainda, a cultura de sangue resulte positiva, o agente etiológico pode não ser identificado por meio das técnicas microbiológicas de rotina. Nas erisipelas, a confirmação diagnóstica, obtida por cultura, ocorre em baixa percentagem dos casos. A coloração por Gram de esfregaços do exsudato, do pus, do líquido ou aspirado da bolha ou da lesão pode evidenciar bactérias. Observam-se cadeias de cocos Gram-positivos nas infecções por EGA, cachos de cocos Gram-positivos, se causadas por $S$ aureus, e bastonetes Gram-positivos nas infecções por clostrídios. As culturas podem ser realizadas com a coleta do aspirado, do fragmento da borda da lesão primária, ou ainda do sangue. As culturas para fungos e micobactérias estão indicadas para os casos atípicos.

Alterações hematológicas, como a leucocitose e elevação da VHS, em geral, são observadas. Os títulos de antiestreptolisina $\mathrm{O}$ (ASO) poderão se elevar após as infecções estreptocócicas, mas, em geral, refletem infecção prévia mais do que eventos clínicos atuais ${ }^{(3)}$. $\mathrm{O}$ exame dermatopatológico auxilia na exclusão de dermatoses inflamatórias não infecciosas. A histologia do tecido excisado define a presença e extensão da infecção necrotizante dos tecidos moles. É um exame útil no diagnóstico da celulite criptocócica, sendo a cultura comprobatória ${ }^{(2)}$.

Entre os exames de imagens, a ressonância magnética auxilia no diagnóstico da celulite infecciosa, aguda, grave, diferenciando entre piomiosite, fasciíte necrotizante e celulite infecciosa com ou sem abscesso. O exame radiográfico das áreas envolvidas se prestam a identificar a presença de gás nos tecidos moles e o comprometimento difuso desses tecidos ${ }^{(2)}$.

Streptococcus pyogenes continuam, surpreendentemente, susceptíveis a antibióticos $\beta$-lactâmicos e numerosos estudos têm demonstrado a eficácia clínica da penicilina no tratamento da maioria das infecções por estreptococos do grupo A. A redução da eficácia da penicilina, na presença de grande concentração do microorganismo, pode ocorrer, justificando a falência da penicilina no controle de infecções estreptocócicas mais graves ${ }^{(2,3)}$. Estafilococos resistentes à penicilina e ampicilina são a regra, e o tratamento empírico das celulites deve ser instituído com cefa- 
lexina, cefadroxila, macrolídeos, clindamicina ou dicloxacilina uso oral, ou com oxacilina, cefalotina ou ceftriaxona, uso endovenoso. Nas demais infecções dos tecidos moles, o isolamento do patógeno contribui para nortear a escolha adequada do antimicrobiano. Na ausência da identificação do agente etiológico, recomenda-se o emprego de terapêutica antimicrobiana, abrangente, contra estafilococos e estreptococos ${ }^{(3)}$. Na Tabela I, estão listados os principais agentes etiológicos e as respectivas indicações da terapêutica antimicrobiana.

\section{SÍNDROMES MEDIADAS POR TOXINAS}

\section{Síndrome da pele escaldada, es- tafilocócica}

A síndrome da pele escaldada, estafilocócica (SPEE) é uma doença epidermolítica, mediada por toxinas, que se caracteriza por eritema, desprendimento generalizado das camadas superficiais da epiderme, envolvendo, principalmente, recémnascidos e lactentes com menos de 2 anos de idade. $\mathrm{O}$ espectro clínico da infecção estafilocócica inclui manifestações cutâneas localizadas e disseminadas, de impetigo bolhoso localizado ou generalizado, e a síndrome da pele escaldada, estafilocócica, como quadro extensivo de epidermólise e descamação ${ }^{(1,2,4)}$.

O agente etiológico, envolvido é o Staphylococcus aureus do grupo II, principalmente o tipo 71, que produz duas exotoxinas, A e B, epidermolíticas ou exfoliativas. A produção de toxinas origina-se de focos de infecção, como conjuntivite purulenta, otite média e infecção nasofaríngea ou, localmente, das lesões do impetigo bolhoso. A presença das bactérias Gram-positivas é observada no local colonizado, sendo ausente nas áreas de epidermólise ${ }^{(2)}$.

$\mathrm{O}$ exame histopatológico evidencia clivagem intraepidérmica, subgranulosa, o que diferencia da clivagem subepidérmica, que ocorre na necrólise epidérmica, tóxica, provocada por drogas ${ }^{(4)}$.
Tabela I: Principais agentes etiológicos e respectivas indicações da terapêutica antimicrobiana para a erisipela/celulite.

\begin{tabular}{c|c|c} 
Agente Etiológico & $\begin{array}{c}\text { Antibióticos de } \\
\text { la Escolha }\end{array}$ & Alternativos
\end{tabular}

Staphylococcus aureus/ $S$. epidermidis

Oxacilina

\begin{tabular}{l|l} 
Oxacilina-sensível & Vancomicina
\end{tabular}

Cefalosporina de $1^{a}$ geração dicloxacilina, macrolídeos ou clindamicina

Teicoplamina

Eritromicina, cefalosporina de $1^{\text {a }}$ geração, claritromicina, azitromicina ou clindamicina

ou $\mathrm{V}$

ou clindamicina

Streptococcus (Grupo B)

Penicilina G Cefalosporina, vancomicina ou ampicilina ou eritromicina

Eritromicina, cefalosporina de $1^{a}$ geração, vancomicina, azitromicina, claritromicina, clindamicina ou cloranfenicol

Penicilina G ou V

$\begin{array}{lll}\text { Haemophilus influenzae } & \begin{array}{l}\text { Amoxacilina }+ \\ \text { ácido clavulínico }\end{array} & \begin{array}{l}\text { Cefuroxima, ceftriaxona ou } \\ \text { cloranfenicol }\end{array}\end{array}$

Pseudomonas aeruginosa

Ceftazidima + amicacina ou cefepime

Imipenem, gentamicina, amicacina ou fluoroquinolona

\begin{tabular}{|c|c|c|}
\hline Vibrio vulnificus & Tetraciclina & $\begin{array}{l}\text { Trimetoprim-sulfametoxazol } \\
\text { ou fluoroquinolona }\end{array}$ \\
\hline
\end{tabular}

Metronidazol, clindamicina, Clostridium perfringens Penicilina G imipenem, tetraciclina, cloranfenicol

Baseado no Manual de Antimicrobianos, Comissão de uso e controle de antimicrobianos (CUCA), Hospital das Clinicas da FMRP-USP, 1999/2000(5).

Os tratamentos tópicos, recomendados são banhos e compressas para desbridamento da epiderme superficial necrótica. Agentes antimicrobianos tópicos, sulfadiazina de prata, bacitracina, mupirocina estão indicados, particularmente, para infecções localizadas, mantendo-se o cuidado de se evitar o uso de tópicos sensibilizantes. Há indicação do tratamento com oxacilina endovenosa, para infecções, com comprometimento extenso da pele. A dicloxacilina oral poderá ser empregada na continuidade do tratamento endovenoso ou para casos mais brandos da doença. A reposição das perdas hidroeletrolíticas deve ser cuidada ${ }^{(1,2)}$. 


\section{Síndrome do choque tóxico}

A síndrome do choque tóxico (SCT) é uma doença mediada por toxinas causada pelo Staphylococcus aureus toxigênico. Ocorre seguindo o padrão menstrual e não-menstrual, com quadro caracterizado pelo início súbito de febre, hipotensão, eritema cutâneomucoso generalizado e, posteriormente, falência de múltiplos sistemas ${ }^{(1,2)}$.

O agente etiológico, $S$. aureus, produtor da toxina 1, é o responsável pela síndrome do choque tóxico (TSCT-1). As infecções graves, causadas por estreptococos do grupo A também podem acarretar condição semelhante à $\mathrm{SCT}^{(3)}$. As manifestações clínicas são resultantes da absorção da TSCT-1, produzida pelo $S$. aureus, toxina que diminui o tono vasomotor e acarreta o extravasamento de líquido intravascular. Conseqüientemente, há o início súbito da hipotensão, seguido de isquemia tecidual e falência de múltiplos órgãos ${ }^{(1,2)}$.

Na SCT, seguindo o padrão menstrual, o uso de tampões vaginais no período menstrual foi implicado como relevante fator de risco. Na SCT, não relacionada ao padrão menstrual, os fatores de risco são constituídos por: presença de feridas cirúrgicas e não-cirúrgicas, tamponamento nasal e infecções puerperais, entre outros. A SCT não menstrual pode estar associada a várias infecções primárias, causadas por S. aureus, bem como à infecção secundária de dermatoses preexistentes. Diabete melito e doença vascular periférica predispõem a SCT estreptocócica ${ }^{(1,2)}$.

O período de incubação é mais curto na SCT do padrão não-menstrual, em geral, 4 dias após intervenções cirúrgicas contaminadas. A SCT padrão menstrual pode se iniciar subitamente, com febre e hipotensão, sensação de formigamento das mãos e pés, seguido da erupção maculopapulosa e pruriginosa. $\mathrm{Na}$ eritrodermia escarlatiforme, generalizada, associada a SCT, as alterações são mais intensas em torno das áreas infectadas. É comum o edema generalizado e subseqüente descamação de mãos e pés. O surgimento de petéquias e bolhas é mais raro. Há evolução com febre, hipotensão e falência de múltiplos órgãos. As complicações renais e do SNC são mais comuns na SCT não menstrual ${ }^{(1,2)}$.

Fitzpatrick et al. (1998) ${ }^{(2)}$ destacaram os critérios para definição de caso clínico de SCT, de acordo com aqueles dos CDC - USA (Centers for disease control and prevention)

Febre: temperatura $\geq 38,9^{0} \mathrm{C}$

Erupção: eritrodermia maculosa, difusa

Descamação: uma a duas semanas após início do quadro, particularmente, das regiões palmoplantares.

Hipotensão: pressão arterial sistólica $\leq 90$ mmHg para adultos. Síncope ou vertigem ortostática.

Comprometimento de três ou mais dos sistemas orgânicos, listados na Tabela II.

O diagnóstico de SCT não menstrual, em geral, é tardio, em virtude da grande variedade de situações clínicas e da sintomatologia associada. As complicações são: hipotensão refratária, síndrome da angústia

Tabela II: Correlação dos sistemas orgânicos e principai s anormalidades clínicas, presentes na síndrome do choque tóxico (SCT).

\section{Sistemas orgânicos Anormalidades clínicas e laboratoriais}

Gastrointestinal Vômitos, diarréia no início do quadro

Muscular $\quad$ Mialgia grave, aumento da fosfoquinase da creatinina $(>2 x x)$

Mucosas Hiperemia vaginal, orofaríngea ou conjuntival

Renal Aumento da uréia ou creatinina $(>2 X X)$, leucocitúria

Hepático Aumento de bilirrubina total, TGO e TGP (>2XX)

Hematológico Plaquetas $\leq 100.000 / \mathrm{ml}$

Quadro de desorientação ou de alterações da consciência, isolado dos episódios de febre e hipotensão, sem sinais neurológicos focais.

Adaptado de FITZPATRICK TB et al. Dermatologia: Atlas e texto, 3a ed., McGraw Hill, 1998. 
respiratória do adulto, cardiomiopatia, arritmias, encefalopatia, insuficiência renal aguda, acidose metabólica, necrose hepática, coagulação intravascular, disseminada. A mortalidade da SCT não-menstrual é mais alta do que a da SCT menstrual ${ }^{(1,2)}$.

A SCT estafilocócica tem, como diagnóstico diferencial, a SCT causada por estreptococo do grupo A. Estudos epidemiológicos e relatos clínicos têm demonstrado associação entre a SCT estreptocócica e cepas de estreptococos do grupo A, portadores da proteína M. Exotoxinas pirogênicas, estreptocócicas, substâncias responsáveis pelo rash cutâneo da febre escarlatina, são suspeitas do envolvimento na patogênese da SCT estreptocócico. A mortalidade da SCT estreptocócica gira em torno de 25 a $50 \%{ }^{(2)}$.

Algumas investigações sugerem que as toxinas estreptocócicas ou estafilocócicas atuariam de modo semelhante aos superantígenos, isto é, teriam a capacidade de interagir, simultaneamente, com MHC, classe II, das células apresentadoras de antígeno e regiões específicas dos receptores dos linfócitos T, na ausência do processo clássico da apresentação de antígenos. A consequiência dessa interação é a síntese concomi- tante das citocinas TNF- $\alpha$, IL-1, IL-6, IL-2 e IFN- $\gamma$. A maciça liberação de tais citocinas é um mecanismo plausível para explicação do choque e falência de órgãos na SCT estreptocócico e estafilocócico ${ }^{(1,3)}$.

Diagnósticos diferenciais da síndrome do choque tóxico( ${ }^{(2)}$

Infecções mediadas por toxinas: síndrome da pele escaldada, estafilocócica, escarlatina, gastroenterites.

Infecções multisistêmicas: choque séptico com infecção localizada (meningococos, pneumoco$\cos$ ), leptospirose, sarampo, síndromes virais (adenovírus, enterovírus).

Doenças não infecciosas: lúpus eritematoso sistêmico, febre reumática aguda, farmacodermia (síndrome de Stevens-Johnson) e artrite reumatóide juvenil.

\section{AGRADECIMENTOS}

Dr. Paulo de Tarso de Oliveira e Castro da Comissão de Uso e Controle de Antimicrobianos do Hospital das Clinicas da Faculdade de Medicina de Ribeirão Preto-USP, pela revisão terapêutica.

SOUZA CS. Soft tissue infections - Erysipela. Cellulitis. Infectious Syndromes Mediated By Toxin. Medicina, Ribeirão Preto, 36: 351-356, apr./dec. 2003.

ABSTRACT - The objective of this review is to approach the etiology and the main clinical aspects, both dermatological and therapeutic of the soft tissue infections and the infectious syndromes mediated by toxins.

UNITERMS - Erysipelas. Cellulitis. Staphylococcal Scalded Skin Syndrome. Toxic Shock Syndrome.

\section{REFERÊNCIAS BIBLIOGRÁFICAS}

1 - TSAO H; SWARTZ MN; WEINBERG AN \& JOHNSON RA. Soft tissue Infections: erysipelas, cellulitis and gangrenous cellulites. In: FREEDBERG IM; EISEN AZ; WOLFF K; AUSTEN KF; GOLDSMITH LA; KATZ SI \& FITZPATRICK TB, eds. Dermatology in general medicine. 5th ed, McGraw Hill, $p$. 2213-2231,1999.

2 - FITZPATRICK TB; JOHNSON RA \& WOLLF K. Infecções bacterianas sistêmicas. In: Dermatologia: Atlas e texto, $3^{\text {a }}$ ed., McGraw Hill, São Paulo, p. 622-678, 1998.
3 - BISNO AL \& STEVENS DL. Streptococcal infections of skin and soft tissues. N Engl J Med 25: 240-244, 1996.

4 - SAMPAIO SAP \& RIVITTI EA. Piodermites e outras dermatoses por bactérias. In: Dermatologia. $2^{\mathrm{a}}$ ed, Artes Médicas, São Paulo, p. 435-452, 2001.

5 - HOSPITAL DAS CLINICAS DA FACULDADE DE MEDICINA DE RIBEIRÃO PRETO - USP. COMISSÃO DE USO E CONTROLE DE ANTIMICROBIANOS (CUCA). Manual de antimicrobianos, HCFMRP-USP, Ribeirão Preto, 1999/2000. 